\title{
Research Article \\ Effect of ZnO on the Thermal Properties of Tellurite Glass
}

\author{
H. A. A. Sidek, S. Rosmawati, B. Z. Azmi, and A. H. Shaari \\ Glass Ceramic and Composite Research Group, Department of Physics, Faculty of Science, Universiti Putra Malaysia, \\ 43400 Serdang, Selangor, Malaysia \\ Correspondence should be addressed to H. A. A. Sidek; sidek@upm.my
}

Received 16 August 2012; Accepted 29 January 2013

Academic Editor: Nigel Wilding

Copyright (C) 2013 H. A. A. Sidek et al. This is an open access article distributed under the Creative Commons Attribution License, which permits unrestricted use, distribution, and reproduction in any medium, provided the original work is properly cited.

\begin{abstract}
Systematic series of binary zinc tellurite glasses in the form $(\mathrm{ZnO})_{x}\left(\mathrm{TeO}_{2}\right)_{1-x}$ (where $x=0$ to 0.4 with an interval of 0.05 mole fraction) have been successfully prepared via conventional melt cast-quenching technique. Their density was determined by Archimedes method with acetone as buoyant liquid. The thermal expansion coefficient of each zinc tellurite glasses was measured using L75D1250 dilatometer, while their glass transition temperature $\left(T_{g}\right)$ was determined by the SETARAM Labsys DTA/6 differential thermogravimetric analysis at a heating rate of $20 \mathrm{~K} \mathrm{~min}^{-1}$. The acoustic Debye temperature and the softening temperature $\left(T_{s}\right)$ were estimated based on the longitudinal $\left(V_{L}\right)$ and shear ultrasonic $\left(V_{s}\right)$ wave velocities propagated in each glass sample. For ultrasonic velocity measurement of the glass sample, MATEC MBS 8000 Ultrasonic Data Acquisition System was used. All measurements were taken at $10 \mathrm{MHz}$ frequency and at room temperature. All the thermal properties of such binary tellurite glasses were measured as a function of $\mathrm{ZnO}$ composition. The composition dependence was discussed in terms of $\mathrm{ZnO}$ modifiers that were expected to change the thermal properties of tellurite glasses. Experimental results show their density, and the thermal expansion coefficient increases as more $\mathrm{ZnO}$ content is added to the tellurite glass network, while their glass transition, Debye temperature, and the softening temperature decrease due to a change in the coordination number $(\mathrm{CN})$ of the network forming atoms and the destruction of the network structure brought about by the formation of some nonbridging oxygen (NBO) atoms.
\end{abstract}

\section{Introduction}

Tellurite glasses are at present the subject of intensive investigations because the glassy phase can be formed over a wide range of concentrations. The application of these types of glasses in areas of optoelectronics such as laser technology and fiber optics and other fields is immense due to their good physical properties, high density, chemical stability, high homogeneity, and relatively high electrical conductivity [1-4].

Even tellurite glasses and glass ceramics are promising choices due to their high refractive index (larger than 2), wideband infrared transmittance (extending up to 6 micrometer), and large third-order nonlinear optical susceptibility. In addition, tellurite glasses combine the attributes of a short wavelength UV edge (about $350 \mathrm{~nm}$ ), good glass stability, rare earth ion solubility, a slow corrosion rate, and relatively low phonon energy $\left(600-850 \mathrm{~cm}^{-1}\right)$ among oxide glass formers [5]. Furthermore, their low transformation temperatures and absence of hygroscopic properties limits the application of phosphate and borate glasses. Based on the information, the use of tellurite glasses may be more advantageous than silicate glasses $[6,7]$.

Another basic system that has good glass-forming ability and used by many researchers is the $\mathrm{ZnO}-\mathrm{TeO}_{2}$ system. Tellurium (IV) oxide in combination with $\mathrm{ZnO}$ forms stables glasses [7]. Zinc tellurite glasses are reported to be a suitable host for optically active rare earth ions because of the wide glass-formation range which is close to the extremum for binary tellurite glasses [8]. $\mathrm{ZnO}-\mathrm{TeO}_{2}$ system was used as a basis for multicomponent optical glass synthesis and has been reported as a useful medium for ultralow loss $\left(1 \mathrm{~dB} 1000 \mathrm{~m}^{-1}\right)$ optical fibers for wavelengths in the $3.5-4 \mu \mathrm{m}$ region [9]. It seems clear from the coverage above that tellurite glasses are strategically important solid materials.

The above indicate undoubtedly the existence of a practical interest in the zinc-tellurium-containing systems as a choice of compositions for super heavy optical flint glasses. Previous studies showed that the glass formation occurs in the zinc tellurite system in the region of the eutectic $(21 \mathrm{~mol} \%$ 
TABle 1: The density, transition temperature, thermal expansion, acoustic Debye temperature, and softening temperature of zinc tellurite glasses.

\begin{tabular}{|c|c|c|c|c|c|c|}
\hline \multirow{2}{*}{$\begin{array}{l}\text { Glass } \\
\text { sample }\end{array}$} & \multirow{2}{*}{$\mathrm{ZnO}-\mathrm{TeO}_{2}(\mathrm{~mol} \%)$} & \multirow{2}{*}{$\begin{array}{l}\text { Density } \\
\left(\mathrm{g} / \mathrm{cm}^{3}\right)( \pm 0.01)\end{array}$} & \multirow{2}{*}{$\begin{array}{l}\text { Thermal expansion coefficient } \\
\qquad\left(\times 10^{-6} \mathrm{~K}^{-1}\right)( \pm 0.01)\end{array}$} & \multicolumn{3}{|c|}{ Temperature (K) } \\
\hline & & & & Transition & Debye & Softening \\
\hline ZT0 & $0-100$ & 4.80 & 12.40 & 658 & 263 & 857 \\
\hline ZT1 & $10-90$ & 5.09 & 12.14 & 654 & 259 & 852 \\
\hline ZT2 & $15-85$ & 5.10 & 12.36 & 653 & 259 & 833 \\
\hline ZT3 & $20-80$ & 5.14 & 12.51 & 646 & 257 & 802 \\
\hline ZT4 & $25-75$ & 5.19 & 12.66 & 647 & 257 & 783 \\
\hline ZT5 & $30-70$ & 5.21 & 12.90 & 638 & 252 & 736 \\
\hline ZT6 & $35-65$ & 5.28 & 12.54 & 637 & 253 & 722 \\
\hline ZT7 & $40-60$ & 5.29 & 12.78 & 633 & 251 & 694 \\
\hline
\end{tabular}

$\mathrm{ZnO}$ ) on the $\mathrm{TeO}_{2}$-rich side of the phase diagram [10]. These types of glasses are characterized by a high refractive index which increases with $\mathrm{TeO}_{2}$ content [11-13].

Apart from their applications, there is a lack of data on structural investigations as well as the thermal properties of these $\mathrm{ZnO}-\mathrm{TeO}_{2}$ glass systems in the literature. Therefore, the aim of this research is to study the effect of zinc on the thermal properties of tellurite glass system in order to understand the fundamental origin of such properties.

\section{Experimental and Materials}

Systematic series of binary zinc tellurite glasses in the form $(\mathrm{ZnO})_{x}\left(\mathrm{TeO}_{2}\right)_{1-x}$ (where $x=0$ to 0.4 with internal of 0.05 mole fraction) have been successfully prepared via melt quenching technique. The density of the glasses was determined by Archimedes method with acetone as buoyant liquid. The preparation of the tellurite-based glass systems and related experimental method has been discussed elsewhere [14-16].

To check the amorphous state, the X-ray diffraction was carried out for each glass sample by using a computercontrolled X'pert Pro Panalytical set. Both longitudinal and shear ultrasonic velocities were measured in different compositions of the glass system by using the MBS8000 Ultrasonic Data Acquisition System at $10 \mathrm{MHz}$ frequency and at room temperature. The thermal expansion coefficient was measured using L75D1250 dilatometer with the rectangular parallelepiped $3 \times 3 \times 6 \mathrm{~mm}^{3}$ of each glass samples. The thermal expansion was obtained over a range of $30^{\circ}$ to $210^{\circ} \mathrm{C}$, while the glass transition temperature $\left(T_{g}\right)$ was determined by the differential thermogravimetric analysis (Setaram instrumentation Labsys DTA/6) at heating rate of $20 \mathrm{~K} \mathrm{~min}^{-1}$. The accuracy in the measurement of $T_{g}$ is $\pm 2^{\circ} \mathrm{C}$.

\section{Results and Discussion}

Table 1 presents the density, transition temperature, thermal expansion, acoustic Debye temperature, and softening temperature of $(\mathrm{ZnO})_{x}\left(\mathrm{TeO}_{2}\right)_{1-x}$ zinc tellurite glasses.

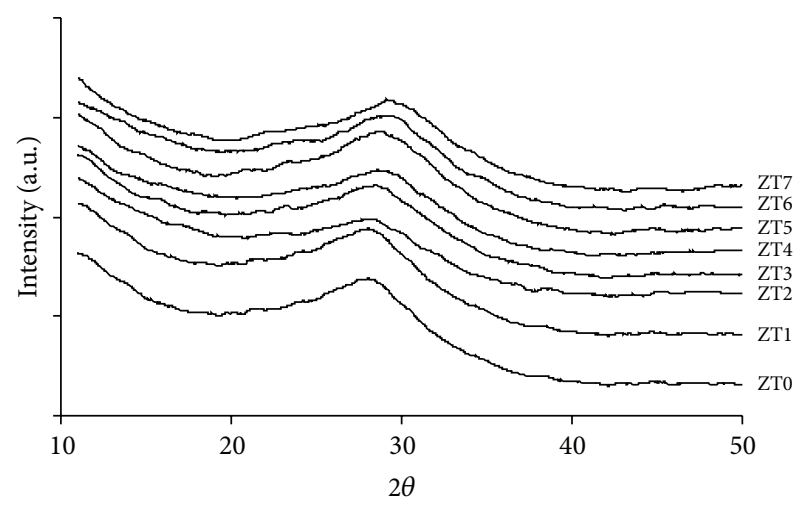

FIGURE 1: The XRD patterns of zinc tellurite and pure tellurite glass.

3.1. XRD Analysis. The XRD patterns of the present glass samples depicted in Figure 1 were found to show no discrete or continuous sharp peaks but broad halo at around $26^{\circ}-$ $30^{\circ}$, which reflected the characteristic of amorphous glass structure. This indicates the absence of long-range atomic arrangement and the periodicity of the three-dimensional network in the glassy materials.

3.2. Density. The density of a glass is an important property capable of evaluating the compactness. The density is affected by the structural softening/compactness, change in coordination number, and dimension of interstitial spaces of the glass. The increase in the density (as depicted in Table 1) can be related to two reasons: The first reason is the replacement of $\mathrm{TeO}_{2}$ by $\mathrm{ZnO}$ which has high relative molecular weight where the molecular weight of $\mathrm{TeO}_{2}$ and $\mathrm{ZnO}$ is 159.6 and 81.38 , respectively. The second reason may be due to the transformation of $\mathrm{TeO}_{3}$ to $\mathrm{TeO}_{4}$ where the formation of $\mathrm{TeO}_{3+1}$ polyhedron has one nonbridging oxygen atom. This increase can be attributed to the zinc ions that occupy the interstitial position, and therefore the threedimensional structure of tellurite glass is not destroyed. These behaviors of the studied glasses are agreed with reported data elsewhere $[4,7]$. 
3.3. Thermal Expansion. Thermal expansion is one of the very important properties of materials for many technological and practical applications. The aim of the present work is to characterize glass thermal expansion coefficient, and their transition temperatures. There is a strong dependence between the glass transition temperature, $T_{g}$, thermal expansion coefficient and the kind of the modifier [17].

The thermal expansion coefficient of a material is a measure of the rate of change in volume and therefore density with temperature. Although the thermal expansion coefficient is actually defined in terms of the volume of the substance, this value is somewhat difficult to measure. As a result, the expansion coefficient for glasses is usually only determined in one direction; that is, the measured value is the linear thermal expansion coefficient, $\alpha_{L}$ :

$$
\alpha_{L}=\frac{\Delta L}{L x \Delta T}
$$

where $L$ is the original length of the sample, $\Delta L$ is the increase in length, and $\Delta T$ is the increase in temperature. Since glasses are usually isotropic materials with relatively small thermal expansion coefficients, $\alpha_{v}=3 \alpha_{L}$ can be used to approximate $\alpha_{v}$ with very little error in calculation.

All reported thermal expansion coefficients for glasses are actually average linear thermal expansion coefficients over some specified temperature ranges. The particular temperature ranges from 0 to $300^{\circ} \mathrm{C}, 20$ to $300^{\circ} \mathrm{C}$, or 25 to $300^{\circ} \mathrm{C}$. The data for experimental studies may be reported for almost any temperature range. Since most linear thermal expansion coefficients lie between 1 and $50 \times 10^{-6} \mathrm{~K}^{-1}$, metallurgists, ceramists, and other material scientists usually report values with units of $\mathrm{ppm} \mathrm{K}^{-1}$. Traditionally, however, glass technologists used $10^{-7} \mathrm{~K}^{-1}$ as the basis for reporting thermal expansion coefficients.

An understanding of how the thermal expansion coefficient varies as a function of the glass composition is needed. The linear $\alpha$ th of any solid material depends strongly on the anharmonic nature of interatomic forces.

Figure 2 shows the plot of thermal expansion coefficient versus chemical composition of binary zinc tellurite glasses at various temperatures and summarized in Table 1.

The thermal expansion coefficient indicates the relation between the volume of a glass and its temperature. This property is a strong function of glass composition. In the range between room temperature and $T_{g}$, the expansion coefficient of the glass was often assumed to be independent of temperature and was defined as $\alpha=\left(\Delta L / L_{0}\right) \Delta T$. From Figure 2 it can be seen that the thermal expansion coefficient increases as the $\mathrm{ZnO}$ content added from 0.10 mole fraction to 0.40 mole fraction.

The substitution of $\mathrm{ZnO}$ might be due to the change of the coordination number of $\mathrm{TeO}_{2}$ from 4 to 3 . This change is associated with the creation of non-bridging oxygens (NBOs) that caused the decrease in rigidity. Further substitution of $\mathrm{ZnO}$, that is, 0.35 mole fraction, decreases the thermal expansion coefficient which can be supported by the earlier work [18]. Further increasing the modifier content stabilizes $\mathrm{TeO}_{4}$ units with NBO. The decrease of thermal expansion

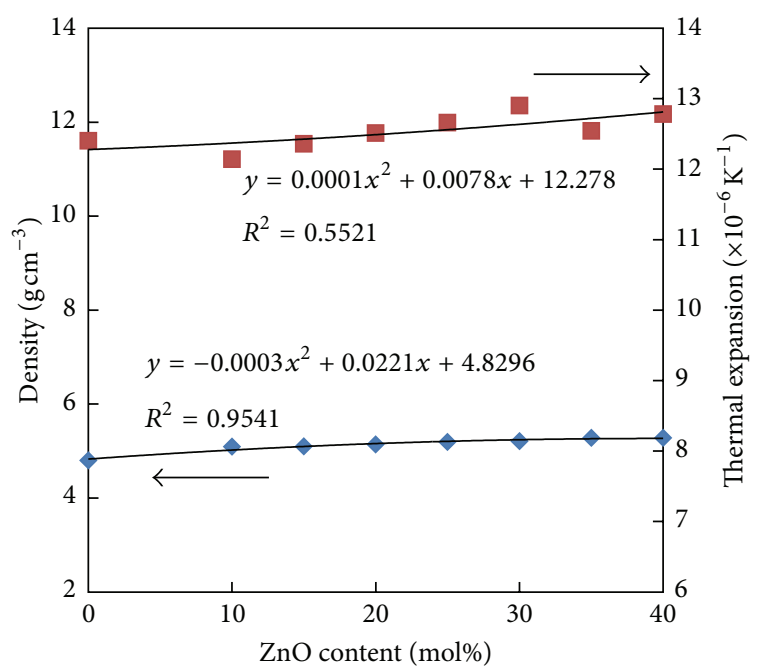

FIgure 2: The density and linear expansion coefficient of $\mathrm{TeO}_{2}-\mathrm{ZnO}$ glasses.

coefficient increased the tightness of the structure. Above 0.35 mole fraction, the conversion of $\mathrm{TeO}_{4}$ to $\mathrm{TeO}_{3}$ occurs again which causes the decrease in rigidity.

3.4. Thermal Stability. Thermal stability is defined as the resistance to permanent change in properties caused solely by heat. Glass stability is defined in terms of resistance to crystallization of a glass during heating. Glass stability is most important during processes involving re-forming of an existing glass. The glass forming ability automatically leads to glass stability [19]. Thermal stability is frequently characterized by the difference in temperature between the onset of the glass transformation range $\left(T_{g}\right)$ and the occurrence of crystallization $\left(T_{x}\right)$ for a sample heated at a specified linear rate. These measurements are routinely carried out using a differential scanning calorimeter (DSC) or differential thermal analyzer (DTA).

The exact definitions of $T_{g}$ and $T_{x}$ are subjected to the preference of the experimenter, as is the choice of the appropriate heating rate used in the study. Typical thermal spectra may contain one or more exothermic peaks due to crystallization of different phases, but the lowest temperature peak is considered in discussing glass stability. Once a significant number of crystals are formed, subsequent events at higher temperatures are not considered important in glass stability.

It is known that the glass transition temperature $\left(T_{g}\right)$ is affected by the alteration of the glass structure, and the structure of the thermally stable glasses is close-packed structure. The glass transition temperature $T_{g}$ helps to reveal the close or loosely packed structure of the glass [20], where the higher single-bond energy in glass network, the more stable the glass-forming system.

3.5. Glass Transition Temperature. Glass transition temperature, $T_{g}$, plays a vital role in understanding the physical properties of glass [21]. DTA curves for the studied glass 


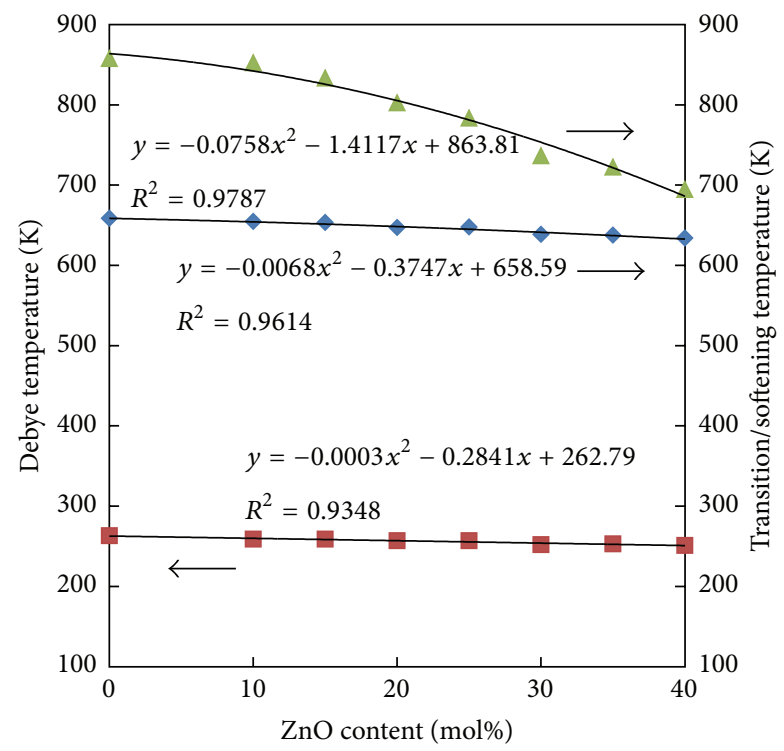

Figure 3: The acoustic Debye, transition and softening temperatures of $\mathrm{ZnO}-\mathrm{TeO}_{2}$ glasses.

samples with different $\mathrm{ZnO}$ contents have been obtained to determine the glass transition temperature $\left(T_{q}\right)$ values. Generally, glasses with close-packed structure will have thermal stability, while those with loose-packed structure will have unstability [17]. In the present investigation, all of the glasses have an endothermic change between 385.21 and $360.52^{\circ} \mathrm{C}$, which attributes to the glass transition temperature, $T_{g}$.

The $\mathrm{Zn}^{2+}$ is incorporated into the glass structure as a network modifier, resulting in loose packing of the glass structure. As a result, a continuous decrease in $T_{g}$ with the increase in network modifier content has been observed (Figure 3). In the present glasses, the decrease in $T_{g}$ values with increase in $\mathrm{Zn}^{2+}$ content contributes to a decrease in thermal stability of the glasses leading to loose-packed structure as discussed elsewhere [21].

The glass transition reflects a change in the coordination number of the network forming atoms and destruction of the network structure brought about by the formation of some non-bridging atoms [22]. The decrease in the glass transition temperature values implies that the number of bridging oxygen groups decreases. This is mainly due to the addition of $\mathrm{ZnO}$ which weakens the bond between each atom sample (increases the number of NBOs atom). The bond is easier to break and hence the $T_{g}$ of the sample decreased. Furthermore, it also implies a decrease in rigidity of the glass network.

3.6. Acoustic Debye Temperature. Acoustic Debye temperature $\left(\theta_{D}\right)$ is a characteristic property of a solid lattice related to its acoustic phonon spectrum [23] where it represents the temperature at which nearly all modes of vibration in a solid are excited [24]. Debye temperature is a characteristic temperature of glass; any modifier added to the host network affects this temperature [25]. Also the increase in the rigidity of the glass is associated with an increase in the lattice vibrations. The observed acoustic Debye temperature, obtained from the ultrasonic velocity data, $[13,24,25]$ is

$$
\Theta_{D}=\left(\frac{h}{k}\right) M_{S}\left(\frac{9 Z N_{A}}{4 \pi V_{m}}\right)^{1 / 3}
$$

where $M_{S}$, the mean velocity, is given by

$$
M_{S}=\left[\left(\frac{1}{V_{L}^{3}}\right)+\left(\frac{2}{V_{s}^{3}}\right)\right]^{-1 / 3}
$$

$h$ the Planck's constant, $k$ the Boltzmann's constant, $N_{A}$ the Avogadro's number, and $Z$ the number of atoms given by

$$
Z=\sum x_{i} L_{i}
$$

where $x$ and $L$ are the mole fraction and number of atoms in the $i$ th oxide.

Regarding the compositional dependence of the Debye temperature, it can be seen that Debye temperature decreases from $263 \mathrm{~K}$ to $251 \mathrm{~K}$ as $\mathrm{ZnO}$ content increases (Figure 3). It decreases when the ultrasonic velocity decreases. The observed decrease in $\theta_{D}$ indicates a monotonic decrease in the total vibrational energy of the system. This is because any of the conceivable vibrational units resulting from the substitution will be of lower energy. Also, the observed decrease in Debye temperature is mainly attributed to change in the number of atoms per unit volume and also the existence of non-bridging oxygen. It also indicates the loosing packing structure of the glasses with creation of NBOs as discussed above. In general the acoustic Debye temperature of the present glasses is particularly sensitive with the addition of $\mathrm{ZnO}$ content.

3.7. Softening Temperature. Softening temperature $\left(T_{s}\right)$ is another important parameter defined as the temperature point at which viscous flow changes to plastic flow. In actual practice, it plays a crucial role in determining the temperature stability of the glass. Softening temperature $\left(T_{s}\right)$ is related to the ultrasonic velocity of shear waves $\left(V_{s}\right)$ by the equation

$$
T_{s}=\frac{V_{s}^{2} M}{C^{2} Z}
$$

where $M$ is the effective molecular weight, $Z$ is the number of atoms in the chemical formula, and $C$ is the constant of proportionality and has the value $507.4\left(\mathrm{~ms}^{-1} \mathrm{~K}^{1 / 2}\right)$ for alumina-silicate glasses and is assumed to be the same for the glasses under investigation.

The higher the value of softening temperature of a glass, the greater the stability of its elastic properties [24, 25]. Values of softening temperature for $\mathrm{ZnO}-\mathrm{TeO}_{2}$ glasses were calculated and presented in Table 1. Figure 3 shows that on addition of $\mathrm{ZnO}$ to $\mathrm{TeO}_{2}$, the softening temperature decreases from $857 \mathrm{~K}$ to $694 \mathrm{~K}$ with increasing $\mathrm{ZnO}$ content. This shows that the stability of the glasses decreases as the network modifier content increases. This change is what may be expected from the decrease of elastic moduli. 
TABLE 2: Nonlinear regression analysis of the variables $\left(\widehat{Y}=\delta \hat{x}^{2}+\beta \hat{x}+\alpha\right)$ for various properties of $\mathrm{ZnO}-\mathrm{TeO}_{2}$ glass.

\begin{tabular}{lccccc}
\hline Variables $(\widehat{Y})$ & $\delta$ & $\beta$ & $\alpha$ & $R^{2}$ & $\%$ change \\
\hline Density & -0.0003 & 0.033 & 4.830 & 10.954 & 0.552 \\
Thermal expansion coefficient & 0.0001 & 0.008 & 38.278 & 0.961 & 0.010 \\
Transition temperature & -0.0068 & -0.375 & 262.76 & -6.41 \\
Acoustic Debye temperature & -0.0006 & -0.275 & 861.08 & -4.56 \\
Softening temperature & -0.1037 & -0.609 & & -19.02 \\
\hline
\end{tabular}

3.8. Regression Analysis. All the current experimental data were analyzed using Microsoft Excel, by fitting regression curves, and the results of the regression coefficients are presented in Table 2. The regression coefficients obtained from each curves are shown in Figures 2 and 3. In Table 2, $\widehat{Y}$ stands for the variables shown in the first column and $\widehat{x}$ is the $\mathrm{ZnO}$ concentration. As can be seen in previous figures, for most of the variables a nonlinear polynomial $\left(\widehat{Y}=\delta \widehat{x}^{2}+\right.$ $\beta \widehat{x}+\alpha)$ gives the best fit.

Except for the softening temperature, the overall results from Table 2 show that the addition of $\mathrm{ZnO}$ with less than $40 \mathrm{~mol} \%$ into the tellurite glass system causes small effect (less than $10 \%$ ) on their thermal properties.

\section{Conclusion}

A number of experimental techniques have been employed to determine a number of important thermal properties of zinc tellurite glass system. The thermal properties of tellurite glasses such as the linear thermal expansion coefficient, the acoustic Debye temperature, glass transformation temperature, $T_{g}$, and softening temperature were studied with respect to $\mathrm{ZnO}$ content. The addition of $\mathrm{ZnO}$ content increases the densities of $\mathrm{ZnO}-\mathrm{TeO}_{2}$ glasses due to a change in crosslink between $\mathrm{TeO}_{2}$ chains and coordination number of $\mathrm{Te}^{2+}$ ions. The addition of $\mathrm{ZnO}$ on $\mathrm{TeO}_{2}$ network also causes the decreasing values of the acoustic Debye, transition, and softening temperatures of $\mathrm{ZnO}-\mathrm{TeO}_{2}$ glasses probably due to the change in $\mathrm{Te}^{2+}$ coordination number. The increase of $\mathrm{ZnO}$ in the tellurite glass system results in lower network rigidity, which in turns results in decrease of most of their thermal properties. Experimental data shows that the density and thermal properties are greatly a strong function of glasses composition. The changes in microstructure glassy network can have an effect on the physical as well as thermal characteristics of zinc tellurite glass.

\section{Acknowledgment}

The authors like to thanks the Universiti Putra Malaysia (UPM) who funded this research project under the Research University Grant Scheme (RUGS 2-2012) Project no. 05-0212-1838RU.

\section{References}

[1] A. I. Sabry and M. M. El-Samanoudy, "Optical, infrared and electrical conductivity of glasses in the $\mathrm{TeO}_{2}-\mathrm{B}_{2} \mathrm{O}_{3}$ system," Journal of Materials Science, vol. 30, no. 15, pp. 3930-3935, 1995.
[2] A. Berthereau, Y. le Luyer, R. Olazcuaga et al., "Nonlinear optical properties of some tellurium (IV) oxide glasses," Materials Research Bulletin, vol. 29, no. 9, pp. 933-941, 1994.

[3] A. Narazaki, K. Tanaka, K. Hirao, T. Hashimoto, H. Nasu, and K. Kamiya, "IR and XPS studies on the surface structure of poled $\mathrm{ZnO}-\mathrm{TeO}_{2}$ glasses with second-order nonlinearity," Journal of the American Ceramic Society, vol. 84, no. 1, pp. 214-217, 2001.

[4] G. D. Khattak and M. A. Salim, "X-ray photoelectron spectroscopic studies of zinc-tellurite glasses," Journal of Electron Spectroscopy and Related Phenomena, vol. 123, no. 1, pp. 47-55, 2002.

[5] T. Sekiya, N. Mochida, and A. Ohtsuka, "Raman spectra of $\mathrm{MO}-\mathrm{TeO}_{2}(\mathrm{M}=\mathrm{Mg}, \mathrm{Sr}, \mathrm{Ba}$ and $\mathrm{Zn})$ glasses," Journal of NonCrystalline Solids, vol. 168, no. 1-2, pp. 106-114, 1994.

[6] T. Kosuge, Y. Benino, V. Dimitrov, R. Sato, and T. Komatsu, "Thermal stability and heat capacity changes at the glass transition in $\mathrm{K}_{2} \mathrm{O}-\mathrm{WO}_{3}-\mathrm{TeO}_{2}$ glasses," Journal of Non-Crystalline Solids, vol. 242, no. 2-3, pp. 154-164, 1998.

[7] V. Kozhukharov, H. Bürger, S. Neov, and B. Sidzhimov, "Atomic arrangement of a zinc-tellurite glass," Polyhedron, vol. 5, no. 3, pp. 771-777, 1986.

[8] D. L. Sidebottom, M. A. Hruschka, B. G. Potter, and R. K. Brow, "Structure and optical properties of rare earth-doped zinc oxyhalide tellurite glasses-practical implications of glass structure," Journal of Non-Crystalline Solids, vol. 222, pp. 282289, 1997.

[9] L. G. van Uitert and S. H. Wemple, " $\mathrm{ZnCl}_{2}$ glass: a potential ultra-low optical fiber material," Applied Physics Letters, vol. 33, no. 57,3 pages, 1978.

[10] H. Bürger, K. Kneipp, H. Hobert, and W. Vogel, "Glass formation, properties and structure of glasses in the $\mathrm{TeO}_{2}-\mathrm{ZnO}$ system," Journal of Non-Crystalline Solids, vol. 151, no. 1-2, pp. 134-142, 1992.

[11] R. El-Mallawany, M. Sidkey, A. Khafagy, and H. Afifi, "Elastic constants of semiconducting tellurite glasses," Materials Chemistry and Physics, vol. 37, no. 3, pp. 295-298, 1994.

[12] R. El-Mallawany, "Quantitative analysis of elastic moduli of tellurite glasses," Journal of Materials Research, vol. 5, no. 10, pp. 2218-2222, 1990.

[13] R. El-Mallawany, "Specific heat capacity of semiconducting glasses: binary vanadium tellurite," Physica Status Solidi (a), vol. 177, no. 2, pp. 439-444, 2000.

[14] Burger H, W. Vogel, and V. Kozhukharov, "IR transmission and properties of glasses in the $\mathrm{TeO}_{2}-\mathrm{R}_{\mathrm{n}} \mathrm{O}_{\mathrm{m}}, \mathrm{R}_{\mathrm{n}} \mathrm{X}_{\mathrm{m}}, \mathrm{R}_{\mathrm{n}}\left(\mathrm{SO}_{4}\right)_{\mathrm{m}}$, $\mathrm{R}_{\mathrm{n}}\left(\mathrm{PO}_{3}\right)_{\mathrm{m}}$ and $\mathrm{B}_{2} \mathrm{O}_{3}$ systems," Infrared Physics, vol. 25, pp. 395$409,1985$.

[15] H. A. A. Sidek, S. P. Chow, Z. A. Talib, and S. A. Halim, "Formation and elastic behavior of lead-magnesium chlorophosphate glasses," The Turkish Journal of Physics, vol. 28, no. 1, pp. 65-71, 2004 . 
[16] H. A. A. Sidek, S. Rosmawati, Z. A. Talib, M. K. Halimah, and W. M. Daud, "Synthesis and optical properties of $\mathrm{ZnO}-\mathrm{TeO}_{2}$ glass system," The American Journal of Applied Sciences, vol. 6, no. 8, pp. 1489-1494, 2009.

[17] R. El-Mallawany, “Tellurite glasses. Part 2. Anelastic, phase separation, debye temperature and thermal properties," Materials Chemistry and Physics, vol. 60, no. 2, pp. 103-131, 1999.

[18] U. Hoppe, E. Yousef, C. Rüssel, J. Neuefeind, and A. C. Hannon, "Structure of zinc and niobium tellurite glasses by neutron and x-ray diffraction," Journal of Physics Condensed Matter, vol. 16, no. 9, pp. 1645-1663, 2004.

[19] J. E. Shelby, Introduction to Glass Science and Technology, The Royal Science of Chemistry, Cambridge, UK, 2nd edition, 2005.

[20] H. Hirashima, H. Kurokawa, K. Mizobuchi, and T. Yoshida, "Electrical conductivity of vandium phosphate glasses containing $\mathrm{ZnO}$ or $\mathrm{GeO}_{2}$," Glastechnische Berichte, vol. 61, no. 6, pp. 151-156, 1988.

[21] A. B. Nishara and V. Rajendran, "Structure and elastic properties of $\mathrm{TeO}_{2}-\mathrm{BaF}_{2}$ glasses," Journal of Physics and Chemistry of Solids, vol. 67, no. 8, pp. 1697-1702, 2006.

[22] H. Mori and H. Sakata, "Low-temperature electrical conduction of $\mathrm{V}_{2} \mathrm{O}_{5}-\mathrm{Sb}_{2} \mathrm{O}_{3}-\mathrm{TeO}_{2}$ glasses," Journal of the Ceramic Society of Japan, vol. 102, no. 9, pp. 852-857, 1994.

[23] A. H. Khafagy, A. A. El-Adawy, A. A. Higazy, S. El-Rabaie, and A. S. Eid, "The glass transition temperature and infrared absorption spectra of: $(70-x) \mathrm{TeO}_{2}+15 \mathrm{~B}_{2} \mathrm{O}_{3}+15 \mathrm{P}_{2} \mathrm{O}_{5}+x \mathrm{Li}_{2} \mathrm{O}$ glasses," Journal of Non-Crystalline Solids, vol. 354, no. 14, pp. 1460-1466, 2008.

[24] M. A. Sidkey, A. Abd El-Moneim, and L. Abd El-Latif, "Ultrasonic studies on ternary $\mathrm{TeO}_{2}-\mathrm{V}_{2} \mathrm{O}_{5}-\mathrm{Sm}_{2} \mathrm{O}_{3}$ glasses," Materials Chemistry and Physics, vol. 61, no. 2, pp. 103-109, 1999.

[25] Y. B. Saddeek and L. Abd El-Latif, "Effect of $\mathrm{TeO}_{2}$ on the elastic moduli of sodium borate glasses," Physica B, vol. 348, no. 1-4, pp. $475-484,2004$. 

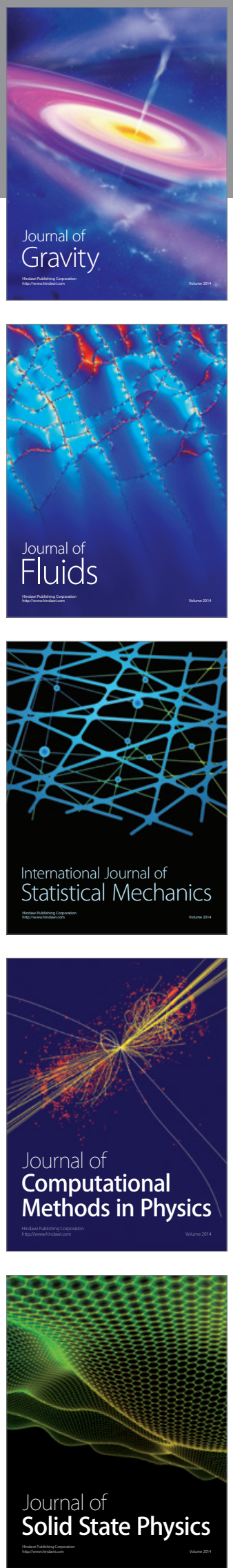

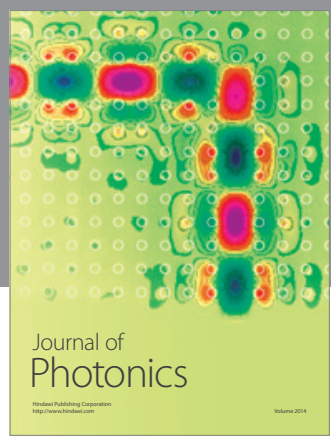

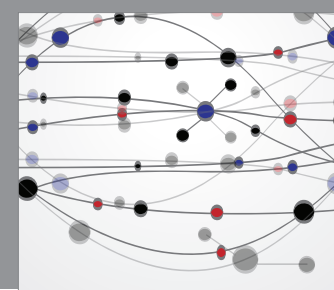

The Scientific World Journal

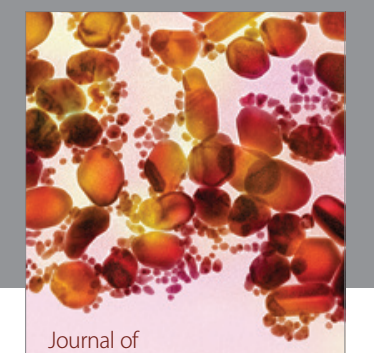

Soft Matter
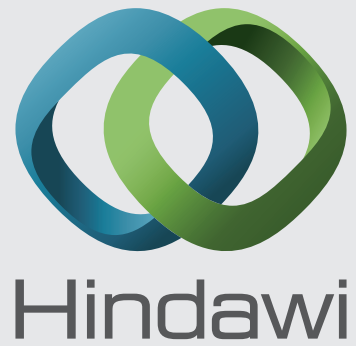

Submit your manuscripts at

http://www.hindawi.com
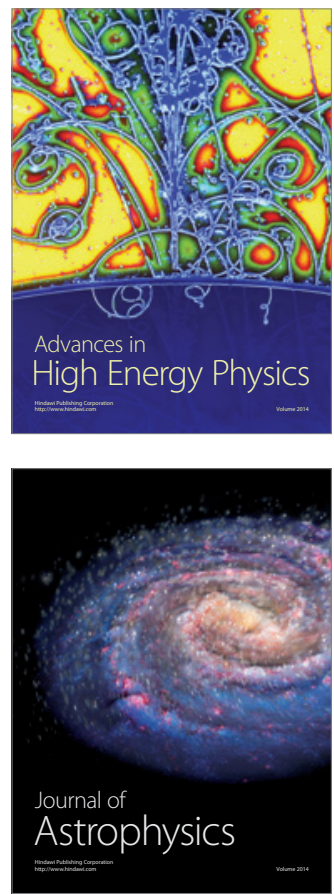
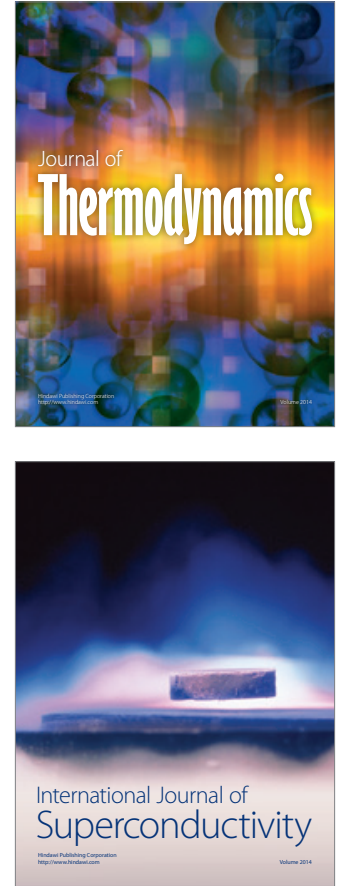
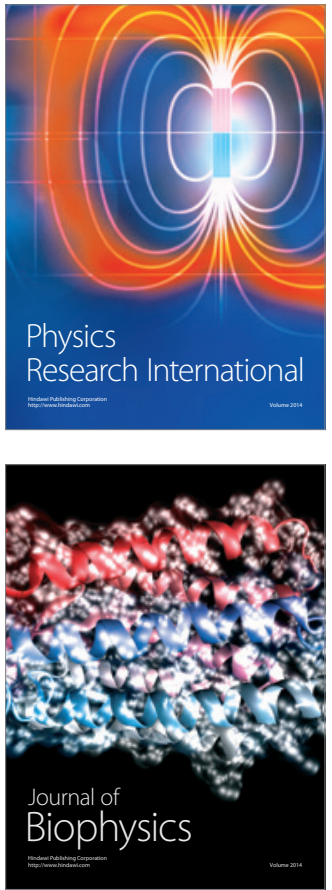
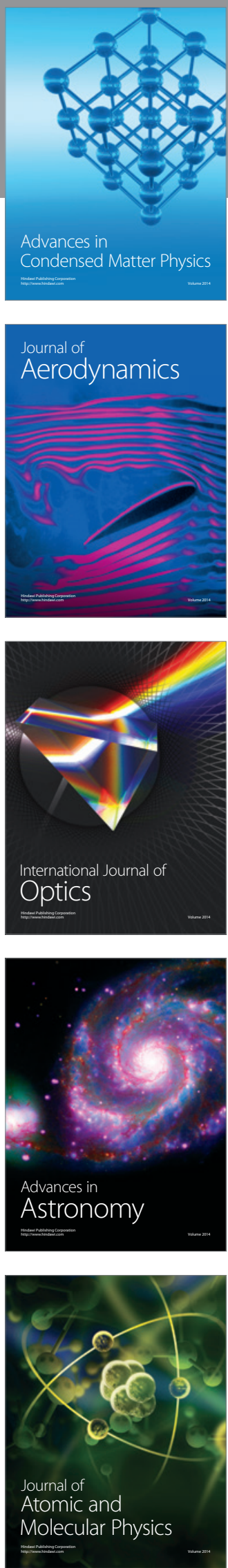